\title{
Optimal Colonoscopy Surveillance Interval after Polypectomy
}

\author{
Tae Oh Kim \\ Department of Internal Medicine, Inje University Haeundae Paik Hospital, Inje University College of Medicine, Busan, Korea
}

The detection and removal of adenomatous polyps and postpolypectomy surveillance are considered important for the control of colorectal cancer (CRC). Surveillance using colonoscopy is an effective tool for preventing CRC after colorectal polypectomy, especially if compliance is good. In current practice, the intervals between colonoscopies after polypectomy are variable. Different recommendations for recognizing at risk groups and defining surveillance intervals after an initial finding of colorectal adenomas have been published. However, high-grade dysplasia and the number and size of adenomas are known major cancer predictors. Based on this, a subgroup of patients that may benefit from intensive surveillance colonoscopy can be identified. Clin Endosc 2016;49:359-363

Key Words: Colorectal neoplasms; Colonoscopy; Colon polypectomy; Surveillance

\section{INTRODUCTION}

The global prevalence of colorectal cancer is increasing, and the incidence in South Korea is rapidly increasing owing to a Westernized diet. Colon carcinogenesis occurs through either the adenoma-carcinoma sequence or a de novo pathway. It is known that over two-thirds of colorectal cancer cases develop from adenomas; therefore, detection and removal of adenomas by colonoscopy is the best way to prevent colorectal cancer. According to an American study in 2008, polyps over $9 \mathrm{~mm}$ in size have been detected in $6 \%$ to $7 \%$ of health screening examinations; the reported adenoma detection rate in Korea varies, but is approximately 9\% during screening examinations. ${ }^{1,2}$ Diagnosis and removal of colorectal polyps is increasing because of the widespread availability of colonoscopy. ${ }^{1,2}$ Consequently, the need for postpolypectomy surveillance is increasing. Follow-up colonoscopy is required to reduce the risk of colorectal carcinogenesis after polypec-

Received: June 16, 2016 Accepted: July 12, 2016

Correspondence: Tae Oh Kim

Department of Internal Medicine, Inje University Haeundae Paik Hospital, Inje University College of Medicine, 875 Haeun-daero, Haeundae-gu, Busan 48108, Korea

Tel: +82-51-797-0200, Fax: +82-51-797-0200, E-mail: kto0440@paik.ac.kr

(cc) This is an Open Access article distributed under the terms of the Creative Commons Attribution Non-Commercial License (http://creativecommons.org/ licenses/by-nc/3.0) which permits unrestricted non-commercial use, distribution, and reproduction in any medium, provided the original work is properly cited. tomy for adenoma. Metachronous lesions were detected in $20 \%$ to $30 \%$ of patients during follow-up colonoscopy 3 to 5 years after polypectomy to remove one or more adenomas. ${ }^{3-7}$ Advanced adenomas ( $>10 \mathrm{~mm}$ in diameter, over $25 \%$ villous component, or high-grade dysplasia) were found in $20 \%$ of these patients, ${ }^{3-8}$ and a small number had invasive colorectal cancer. ${ }^{5,9-14}$ In addition, interval cancer was reported during an adequate follow-up period after screening colonoscopy, ${ }^{15-17}$ and $19 \%$ to $27 \%$ of such interval cancers are known to be caused by incomplete removal of polyps. ${ }^{9,18,19}$ Enhanced colonoscopy surveillance may be needed for screening of patients at high risk of colorectal carcinogenesis, for prediction of progressive colorectal tumor development, management of incompletely removed polyps, and appropriate follow-up.

\section{SUBJECTS}

Follow-up colonoscopy is required because the risk of colorectal cancer after polypectomy is higher than that in patients without polyps. ${ }^{20}$ An appropriate interval for follow-up colonoscopy was recommended in Korea in 2012, based on features of polyps detected by colonoscopy and the risk of progression to an advanced neoplasm during this interval. It is known that number, size, and histological characteristics of adenomas should be considered in postpolypectomy surveillance. The first risk factor is the number of adenomas. The 
probability of detecting an advanced adenoma or tumor is increased when the number of adenoma is 3 or more. According to previous studies that evaluated the correlation between risk of advanced neoplasm and the number of adenomas found during follow-up, ${ }^{21-29}$ the risk increases with the number of adenomas: combined odds ratio (OR) 1.93 (95\% confidence interval [CI], 1.51 to 2.45) and combined hazard ratio (HR) 2.20 (95\% CI, 1.49 to 2.90). The risk of neoplasm development is especially increased in patients with three or more adenomas: combined OR 2.84 (95\% CI, 1.26 to 6.39) and combined HR 2.20 (95\% CI, 1.40-3.46). Thus, established international guidelines recommend follow-up in 3 years in patients with three or more adenomas. Several other guidelines recommend early follow-up for cases with multiple adenomas. The British Society of Gastroenterology-Association of Coloproctology of Great Britain and Ireland guidelines define cases with five or more adenomas, or three or more adenomas including an adenoma over $1 \mathrm{~cm}$ in size, as high-risk, and recommend follow-up after 1 year. ${ }^{30}$ The US Multi-Society Task Force on Colorectal Cancer-American Cancer Society guidelines recommend follow-up in 3 years, and consideration of familial polyposis in cases with 10 or more adenomas. ${ }^{31}$ Moreover, several guidelines recommend follow-up after 1 year for cases with five or more adenomas or with three or more polyps including adenomas over $1 \mathrm{~cm}$ in size. In cases with detection and removal of 10 or more polyps, familial polyposis should be considered and examination of family members should be recommended. Polyps are categorized based on size. Diminutive polyps are $<5 \mathrm{~mm}$ in size, small polyps are between 6 and $9 \mathrm{~mm}$, and large polyps are larger than $10 \mathrm{~mm}$. According to studies evaluating the risk of development of an advanced neoplasm based on the size of a preexisting adenoma, ${ }^{21-25,27-29}$ the risk is not significantly increased for adenomas between 5 and $10 \mathrm{~mm}$ in comparison with the risk for those under 5 $\mathrm{mm}$. However, the risk of development of an advanced neoplasm is increased for adenomas over $10 \mathrm{~mm}$ in size, with a rate two times higher than in cases with adenomas under $10 \mathrm{~mm}$. Larger adenomas include more villous components and are more likely to show advanced pathology; therefore, a maximum $32 \%$ of polyp over $20 \mathrm{~mm}$ are reported to include malignant portions. ${ }^{32,33}$ It is important to assess pathologic completeness when larger sessile polyps are removed, but sessile polyps over $20 \mathrm{~mm}$ are difficult to remove with conventional snare polypectomy, and most are removed by piecemeal resection. ${ }^{34,35}$ Follow-up after 1 year is not mandatory for polyps between 1 and $2 \mathrm{~cm}$ in size, but should be performed in 1 year in the case of incomplete removal. Determination of completeness is important for sessile polyps over $2 \mathrm{~cm}$ in size, and follow-up study after 6 to 12 months is required if completeness is not confirmed. The definition of a polyp as a tubu- lar or villous adenoma has been controversial. However, cases with over $20 \%$ to $25 \%$ villous components in a preexisting adenoma are defined as tubulovillous or villous adenomas; several studies have reported that the risk of development of an advanced neoplasm is significantly increased in patients with tubulovillous or villous adenomas, compared with patients with tubular adenoma alone: combined OR 1.51 (95\% CI, 1.16 to 1.97 ) and combined HR 1.83 (95\% CI, 1.15 to 2.89 ). ${ }^{21,22,24,27}$ A Korean study reported that the risk of development of an advanced adenoma is not increased for the villous adenoma component in a preexisting adenoma (HR, 1.48; 95\% CI, 0.74 to 2.95$).{ }^{29}$ However, Yang et al. ${ }^{36}$ reported that the risk of development of an advanced adenoma is significantly increased with tubulovillous or villous pathology (OR, 8.1; 95\% CI, 4.2 to 15.6), in a 16-year follow-up study after adenoma removal by sigmoidoscopy, and suggested that tubulovillous or villous pathology is the most important predictive factor for risk of advanced neoplasm after polypectomy, along with highgrade dysplasia. An increasing trend for the risk of advanced neoplasm was observed in cases with high-grade dysplasia detected by colonoscopy, compared to cases with low-grade dysplasia: combined OR 1.33 (95\% CI, 0.85 to 2.09 ) and combined HR 1.69 (95\% CI, 1.14 to 2.50 ). ${ }^{21,22,27}$ Stage adjustment at follow-up is required for such cases, but Martínez et al. ${ }^{3}$ reported that the risk is not high. A meta-analysis by Saini et al. ${ }^{37}$ recommends follow-up after 3 years, because high-grade dysplasia and the number of adenomas are the most meaningful factors in the prediction of increased risk for advanced adenoma: combined relative risk 1.84 (95\% CI, 0.53 to 8.93). It was recently reported that serrated polyps progress to colorectal cancer through a pathway different from the adenoma-carcinoma sequence. ${ }^{38}$ Sessile serrated adenomas include hyperplastic polyps, traditional serrated adenomas, and mixed adenomatous and hyperplastic polyps, which have serrated pathological architecture. ${ }^{39}$ Serrated polyps mostly occur in the right colon, and most are associated with BRAF and/or MSI-high mutations, and are predicted to rapidly progress to colorectal cancer. The combined OR in serrated polyp cases at risk for development of advanced neoplasm was 1.98 (95\% CI, 1.24 to 3.15); moreover, the presence of a serrated polyp over $10 \mathrm{~mm}$ in size reportedly increases the risk of development of an advanced neoplasm. ${ }^{40}$ The correlation between location and risk of neoplasm has recently been studied. The risk of a progressive neoplasm has a combined OR of 1.73 (95\% CI, 1.48 to 2.01) when the adenoma is found in the right colon, defined as the colon from cecum to transverse colon or splenic flexure, compared to adenoma located in the left colon. ${ }^{24,28,38}$ Further investigation is required to determine whether an adenoma in the right colon is a risk factor for advanced neoplasm because colonoscopy may miss a tumor owing to the 
Table 1. Summary of Guidelines for Postpolypectomy Surveillance

\begin{tabular}{|c|c|c|c|c|}
\hline & Guideline society & Initial interval & $\begin{array}{l}\text { Subsequent interval if } \\
\text { FU colonoscopy shows } \\
\text { only low-risk adenomas }\end{array}$ & $\begin{array}{c}\text { Subsequent interval if } \\
\text { FU colonoscopy shows } \\
\text { no adenomas }\end{array}$ \\
\hline \multicolumn{5}{|l|}{ Low risk } \\
\hline 1-2 Small adenomas ${ }^{\mathrm{a})}$ & $\begin{array}{l}\text { Task force } \\
\text { ACG }^{\text {b) }} \\
\text { ASGE } \\
\text { BSG }\end{array}$ & $\begin{array}{l}5-10 \mathrm{yr} \\
5 \mathrm{yr} \\
\geq 5 \mathrm{yr} \\
5 \mathrm{yr} \text { or no surveillance }\end{array}$ & $\begin{array}{l}5-10 \mathrm{yr} \\
\text { Not specified } \\
\geq 5 \mathrm{yr} \\
5 \mathrm{yr} \text { or no surveillance }\end{array}$ & $\begin{array}{l}\text { Not specified } \\
5 \mathrm{yr} \\
\geq 5 \mathrm{yr} \\
\text { No surveillance }\end{array}$ \\
\hline \multicolumn{5}{|l|}{ Intermediate risk } \\
\hline $\begin{array}{l}\text { Advanced neoplasm }{ }^{\text {c) }} \text { or 3-10 } \\
\text { small adenomas }\end{array}$ & $\begin{array}{l}\text { Task force } \\
\text { ACG }^{\text {b) }} \\
\text { ASGE } \\
\text { BSG }\end{array}$ & $\begin{array}{l}3 \mathrm{yr} \\
3 \mathrm{yr} \\
3 \mathrm{yr} \\
3 \mathrm{yr}\end{array}$ & $\begin{array}{l}5 \text { yr } \\
\text { Not specified } \\
\text { Not specified } \\
3 \text { yr }\end{array}$ & $\begin{array}{l}5 \mathrm{yr} \\
5 \mathrm{yr} \\
\geq 5 \mathrm{yr} \\
3 \mathrm{yr}\end{array}$ \\
\hline \multicolumn{5}{|l|}{ High risk } \\
\hline Small adenomas $>10$ & $\begin{array}{l}\text { Task force } \\
\text { ACG }^{\text {b) }} \\
\text { ASGE } \\
\text { BSG }\end{array}$ & $\begin{array}{l}<3 \mathrm{yr} \\
\text { Not specified } \\
<3 \mathrm{yr} \\
1 \mathrm{yr}\end{array}$ & $\begin{array}{l}\text { Not specified } \\
\text { Not specified } \\
\text { Not specified } \\
3 \mathrm{yr}\end{array}$ & $\begin{array}{l}\text { Not specified } \\
\text { Not specified } \\
5 \mathrm{yr} \\
3 \mathrm{yr}\end{array}$ \\
\hline Large sessile adenoma & $\begin{array}{l}\text { Task force } \\
\text { ACG }^{\text {b) }} \\
\text { ASGE } \\
\text { BSG }\end{array}$ & $\begin{array}{l}2-6 \mathrm{mo} \\
3-6 \mathrm{mo} \\
2-6 \mathrm{mo} \\
3 \mathrm{mo}\end{array}$ & $\begin{array}{l}\text { Customized } \\
\text { Not specified } \\
\text { Customized } \\
\text { Customized }\end{array}$ & $\begin{array}{l}\text { Customized } \\
\text { Not specified } \\
\text { Customized } \\
1 \mathrm{yr}^{\mathrm{d})}\end{array}$ \\
\hline
\end{tabular}

By US Multi-Society Task Force on Colorectal Cancer (Task Force), ACG, ASGE, and BSG.

FU, follow-up; ACG, American College of Gastroenterology; ASGE, American Society of Gastrointestinal Endoscopy; BSG, British Society of Gastroenterology.

${ }^{\text {a) }}$ Small adenomas are defined as tubular adenomas $<1 \mathrm{~cm}$ in size; ${ }^{\text {b) }} \mathrm{ACG}$ guidelines note that selected low-risk patients might not need surveillance at all, but do not further elaborate; ${ }^{c}$ Advanced neoplasm is defined as villous or tubulovillous adenoma, adenoma with high-grade dysplasia, or a tubular adenoma $\geq 1 \mathrm{~cm}$ in size; ${ }^{\mathrm{d}} \mathrm{BSG}$ guidelines recommend repeating colonoscopy in 1 year after confirmation of complete removal, then every 3 years.

Table 2. Index Colonoscopy Findings Related to an Increased Risk of Subsequent Neoplasia

Index colonoscopy findings related to an increased risk of subsequent neoplasia, any of the followings

Three or more adenomas

Any adenoma(s) larger than $10 \mathrm{~mm}$

Any tubulovillous or villous adenoma(s)

Any adenoma(s) with high-grade dysplasia

Any serrated polyp(s) larger than $10 \mathrm{~mm}$

anatomical characteristics of the right colon, which has sharp curves and distinct haustra; moreover, cancer in the right colon can be caused by the serrated pathway and can be affected by individual patient features and environmental factors. The Korean 2012 guidelines recommend surveillance 5 years after polypectomy for groups that are not at a high risk for advanced neoplasm development; less frequent follow-up is recommended for cases with previous colonoscopy findings related to an increased risk, even if the findings of current colonoscopy suggest no increased risk. Follow-up colonoscopy 3 years after polypectomy is recommended for cases with a high risk of carcinogenesis. However, the follow-up interval should be reduced when well-known conditions are not satisfied, or based on previous colonoscopy findings, completeness of removal, health status, family history, and past medical history (Table 1).

\section{CONCLUSIONS}

The prevalence of colorectal cancer is increasing, and adequate postoperative surveillance is required for patients who undergo polypectomy during colonoscopy, because of higher risk for development of an advanced neoplasm. An increased 
risk of subsequent neoplasia occurs because of polypectomy of three or more adenomas, any adenomas larger than 10 $\mathrm{mm}$, any tubulovillous or villous adenoma, any adenoma with high-grade dysplasia, or any serrated polyp larger than 10 $\mathrm{mm}$ (Table 2). Patients with any of these findings are defined as a high-risk group, and colonoscopy 3 years after complete removal is recommended. In addition, the surveillance period can be reduced based on previous colonoscopy findings, completeness of removal, health status, family history, and past medical history; follow-up colonoscopy at 5 years after polypectomy is recommended for low- or intermediate-risk patients. Recommendations from other countries cannot be applied because the Korean reimbursement system is based on cost-effectiveness. Therefore, management of polyps requires further cost-effectiveness analysis relevant to health care in Korea.

\section{Conflicts of Interest}

The author has no financial conflicts of interest.

\section{REFERENCES}

1. The National Health Insurance Corporation. National Health Insurance Statistical Yearbook for 2009 [Internet]. Seoul: The National Health Insurance Corporation; c2011 [cited 2016 Jul 20]. Available from: http:// www.nhic.or.kr.

2. Health Insurance Policy Research Institute, The National Health Insurance Corporation. Trend of studies about economic evaluation of the cancer screening programs [Internet]. Seoul: The National Health Insurance Corporation; c2011 [cited 2016 Jul 20]. Available from: http://www. nhic.or.kr.

3. Martínez ME, Sampliner R, Marshall JR, Bhattacharyya AK, Reid ME, Alberts DS. Adenoma characteristics as risk factors for recurrence of advanced adenomas. Gastroenterology 2001;120:1077-1083.

4. Schatzkin A, Lanza E, Corle D, et al. Lack of effect of a low-fat, high-fiber diet on the recurrence of colorectal adenomas. Polyp Prevention Trial Study Group. N Engl J Med 2000;342:1149-1155.

5. Baron JA, Cole BF, Sandler RS, et al. A randomized trial of aspirin to prevent colorectal adenomas. N Engl J Med 2003;348:891-899.

6. Winawer SJ, Zauber AG, Ho MN, et al. Prevention of colorectal cancer by colonoscopic polypectomy. The National Polyp Study Workgroup. N Engl J Med 1993;329:1977-1981.

7. Lieberman DA, Weiss DG, Harford WV, et al. Five-year colon surveillance after screening colonoscopy. Gastroenterology 2007;133:1077-1085.

8. Winawer SJ, Zauber AG, O'Brien MJ, et al. Randomized comparison of surveillance intervals after colonoscopic removal of newly diagnosed adenomatous polyps. The National Polyp Study Workgroup. N Engl J Med 1993;328:901-906.

9. Robertson DJ, Greenberg ER, Beach M, et al. Colorectal cancer in patients under close colonoscopic surveillance. Gastroenterology 2005;129:34-41.

10. Alberts DS, Martínez ME, Roe DJ, et al. Lack of effect of a high-fiber cereal supplement on the recurrence of colorectal adenomas. Phoenix Colon Cancer Prevention Physicians' Network. N Engl J Med 2000;342:1156-1162.

11. Bertagnolli MM, Eagle CJ, Zauber AG, et al. Celecoxib for the prevention of sporadic colorectal adenomas. N Engl J Med 2006;355:873-884

12. Arber N, Eagle CJ, Spicak J, et al. Celecoxib for the prevention of col- orectal adenomatous polyps. N Engl J Med 2006;355:885-895.

13. Pabby A, Schoen RE, Weissfeld JL, et al. Analysis of colorectal cancer occurrence during surveillance colonoscopy in the dietary Polyp Prevention Trial. Gastrointest Endosc 2005;61:385-391.

14. Farrar WD, Sawhney MS, Nelson DB, Lederle FA, Bond JH. Colorectal cancers found after a complete colonoscopy. Clin Gastroenterol Hepatol 2006;4:1259-1264.

15. Rabeneck L, Paszat LF, Saskin R, Stukel TA. Association between colonoscopy rates and colorectal cancer mortality. Am J Gastroenterol 2010;105:1627-1632.

16. Singh H, Turner D, Xue L, Targownik LE, Bernstein CN. Risk of developing colorectal cancer following a negative colonoscopy examination: evidence for a 10-year interval between colonoscopies. JAMA 2006;295:2366-2373.

17. Singh H, Nugent Z, Demers AA, Bernstein CN. Rate and predictors of early/missed colorectal cancers after colonoscopy in Manitoba: a population-based study. Am J Gastroenterol 2010;105:2588-2596.

18. Leung K, Pinsky P, Laiyemo AO, Lanza E, Schatzkin A, Schoen RE. Ongoing colorectal cancer risk despite surveillance colonoscopy: the Polyp Prevention Trial Continued Follow-up Study. Gastrointest Endosc 2010;71:111-117.

19. Robertson DJ, Lieberman DA, Winawer SJ, et al. Interval cancer after total colonoscopy: results from a pooled analysis of eight studies. Gastroenterology 2008;134(4 Suppl 1):A111-A112.

20. Citarda F, Tomaselli G, Capocaccia R, Barcherini S, Crespi M; Italian Multicentre Study Group. Efficacy in standard clinical practice of colonoscopic polypectomy in reducing colorectal cancer incidence. Gut 2001;48:812-815

21. Jørgensen OD, Kronborg O, Fenger C. A randomized surveillance study of patients with pedunculated and small sessile tubular and tubulovillous adenomas. The Funen Adenoma Follow-up Study. Scand J Gastroenterol 1995;30:686-92.

22. Bertario L, Russo A, Sala P, et al. Predictors of metachronous colorectal neoplasms in sporadic adenoma patients. Int J Cancer 2003;105:82-87.

23. Martínez ME, Baron JA, Lieberman DA, et al. A pooled analysis of advanced colorectal neoplasia diagnoses after colonoscopic polypectomy. Gastroenterology 2009;136:832-841.

24. Noshirwani KC, van Stolk RU, Rybicki LA, Beck GJ. Adenoma size and number are predictive of adenoma recurrence: implications for surveillance colonoscopy. Gastrointest Endosc 2000;51(4 Pt 1):433-437.

25. Nusko G, Mansmann U, Kirchner T, Hahn EG. Risk related surveillance following colorectal polypectomy. Gut 2002;51:424-428.

26. Kim JB, Han DS, Lee HL, et al. The recurrence rate of colon polyp after polypectomy and the interval of surveillance colonoscopy: predictors of early development of advanced polyp. Korean J Gastroenterol 2004;44:77-83.

27. Pinsky PF, Schoen RE, Weissfeld JL, et al. The yield of surveillance colonoscopy by adenoma history and time to examination. Clin Gastroenterol Hepatol 2009;7:86-92.

28. Huang Y, Gong W, Su B, et al. Recurrence and surveillance of colorectal adenoma after polypectomy in a southern Chinese population. J Gastroenterol 2010;45:838-845.

29. Chung SJ, Kim YS, Yang SY, et al. Five-year risk for advanced colorectal neoplasia after initial colonoscopy according to the baseline risk stratification: a prospective study in 2452 asymptomatic Koreans. Gut 2011;60:1537-1543.

30. Cairns SR, Scholefield JH, Steele RJ, et al. Guidelines for colorectal cancer screening and surveillance in moderate and high risk groups (update from 2002). Gut 2010;59:666-689.

31. Winawer SJ, Zauber AG, Fletcher RH, et al. Guidelines for colonoscopy surveillance after polypectomy: a consensus update by the US Multi-Society Task Force on Colorectal Cancer and the American Cancer Society. Gastroenterology 2006;130:1872-1885.

32. Nivatvongs S, Snover DC, Fang DT. Piecemeal snare excision of large sessile colon and rectal polyps: is it adequate? Gastrointest Endosc 
1984;30:18-20.

33. Seo GJ, Sohn DK, Han KS, et al. Recurrence after endoscopic piecemeal mucosal resection for large sessile colorectal polyps. World J Gastroenterol 2010;16:2806-2811.

34. Saito Y, Fukuzawa M, Matsuda T, et al. Clinical outcome of endoscopic submucosal dissection versus endoscopic mucosal resection of large colorectal tumors as determined by curative resection. Surg Endosc 2010;24:343-352

35. Seitz U, Bohnacker S, Seewald S, Thonke F, Soehendra N. Long-term results of endoscopic removal of large colorectal adenomas. Endoscopy 2003;35:S41-S44.

36. Yang G, Zheng W, Sun QR, et al. Pathologic features of initial adenomas as predictors for metachronous adenomas of the rectum. J Natl Cancer
Inst 1998;90:1661-1665.

37. Saini SD, Kim HM, Schoenfeld P. Incidence of advanced adenomas at surveillance colonoscopy in patients with a personal history of colon adenomas: a meta-analysis and systematic review. Gastrointest Endosc 2006;64:614-626.

38. Leggett $B$, Whitehall V. Role of the serrated pathway in colorectal cancer pathogenesis. Gastroenterology 2010;138:2088-2100.

39. Terdiman JP, McQuaid KR. Surveillance guidelines should be updated to recognize the importance of serrated polyps. Gastroenterology 2010;139:1444-1447.

40. Hong SN, Yang DH, Kim YH, et al. Korean guidelines for post-polypectomy colonoscopic surveillance. Korean J Gastroenterol 2012;59:99-117. 